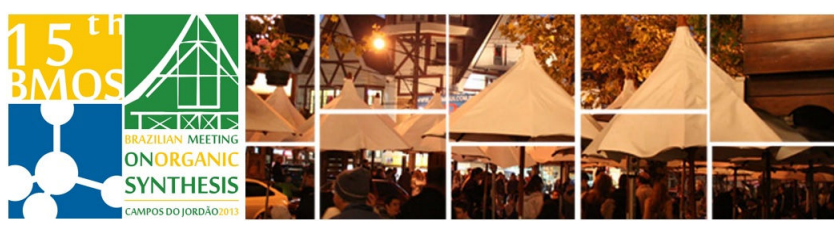

\title{
Sugar-based Catalyst for the Highly Diastereoselective Desymmetrization of dbas
}

\section{Jaqueline R. Gonçalves, Talita N. Duarte, Danielle L. J. Pinheiro and Giovanni W. Amarante*}

*giovanni.amarante@ufjf.edu.br

Keywords: Michael Addition, Desymmetrization, Organocatalysis, Carbohydrate

\section{INTRODUCTION}

Carbohydrates as catalysts have been explored by several research groups due to structural diversity and their chirality. Particularly in the field of organocatalysis they appear as alternative in the synthesis of different catalysts with different backbones. ${ }^{1}$ Recently, we described a diastereoselective Michael addition between enones and azlactones by using (+/-)-CSA as a catalyst. ${ }^{2}$ In this diastereoselective version only unfunctionalized dibenziledeno acetone (dba) was described. Thus, in this communication we show our results on a Brønsted acid catalyzed stereoselective desymmetrization of dbas.

\section{RESULTS AND DISCUSSION}

Our studies began with the preparation of the new catalysts 1 and 2 , which can be easily prepared in five steps from D-galactose.

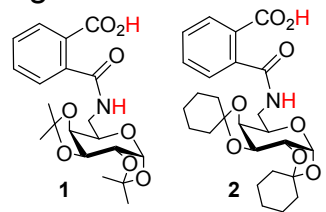

Figure 1. Designed organocatalysts based on sugar.

To our satisfaction using $10 \mathrm{~mol} \%$ of both 1 or 2 catalyzes the reaction between azlactone 3 and $\mathrm{dba}$ 4, providing the Michael adduct $\mathbf{5 a}$ in moderate yield, however, excellent diastereoselectivity was achieved, > 20:1 dr (Table 1). By using the catalyst 1 the corresponding product was isolated in only $35 \%$ yield.

At this point we start the evaluation of substrates. For the first time functionalization on the $\mathrm{dba}$ structure was well tolerated. Desymmetrization of symmetrical dbas containing chlorine or fluorine gave the corresponding Michael-type products in good yields and perfect control of both regio- and stereochemistry. Unfortunately, no enantiomeric excess was observed.
Table 1. Diastereoselective Michael-type addition of azlactones to dbas ${ }^{[a]}$.

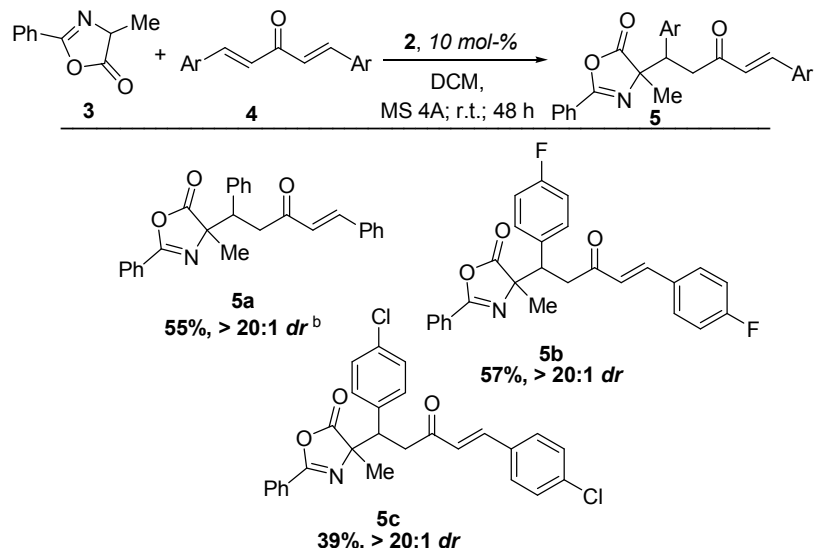

*[a] Reactions were carried out using $0.2 \mathrm{mmol}$ of $3,0.02 \mathrm{mmol}$ of $2(10 \mathrm{~mol} \%)$, and $0.21 \mathrm{mmol}$ of 4 in DCM $(0.2 \mathrm{M}$ in azlactone). [b] Determined by ${ }^{1} \mathrm{H}$ NMR analysis of the crude reaction mixture.

\section{CONCLUSION}

In summary, a Brønsted acid catalyzed regio- and diastereoselective desymmetrization of dbas in presence of azlactones is presented. A new $\sigma \mathrm{C}-\mathrm{C}$ bond and two stereogenic centers are created, one of them a quaternary center. Besides, for the first time, the diastereoselective desymmetrization of functionalized dbas catalyzed by a Brønsted acid is reported. Studies on the design of new catalysts, substrate scope as well as mechanisthical investigations are ongoing and will be reported in due course.

\section{ACKNOWLEDGEMENTS}

FAPEMIG, CAPES, UFJF, CNPq and Rede Mineira de Química for financial support.

\section{REFERENCES}

${ }_{1}^{1}$ Ávila, E. P.; Amarante, G. W. ChemCatChem 2012, 4, 1713.

2 Ávila, E. P.; De Mello, A. C.; Diniz, R.; Amarante, G. W. Eur. J. Org. Chem. 2013, 10, 1881 